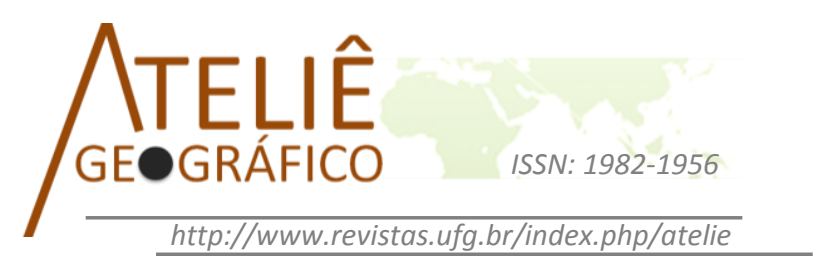

\title{
Rodadas do Uruguai e Doha e as negociações agrícolas nos três pilares: acesso a mercados, apoio interno e subsídios às exportações
}

\author{
Rounds of Uruguay and Doha and agricultural \\ negotiations in the three pillars: market access, domestic \\ support and export subsidies
}

\section{Rondas de Uruguay y de Doha y negociaciones agrícolas en los tres pilares: acceso a los mercados, ayuda interna y subvenciones a la exportación}

\author{
Tamara Silvana Menuzzi Diverio \\ Universidade de Cruz Alta (UNICRUZ) \\ tamara.diverio@domalberto.edu.br
}

\begin{abstract}
Resumo
Neste artigo busca-se fazer reflexões sobre as Rodadas do Uruguai e Doha e as negociações agrícolas nos três pilares: acesso a mercados, apoio interno e subsídios às exportações. Para tanto, serão abordados temas referentes à reestruturação da ordem mundial no período Pós II Guerra, quando as discussões sobre comércio passaram a consolidar um processo de negociações multilaterais e será apresentado um breve histórico sobre a criação, surgimento e evolução do GATT. As informações têm como base o Acordo Agrícola da Rodada do Uruguai e a declaração de Doha, assim como conhecimentos adquiridos nas entrevistas com representantes dos atores brasileiros envolvidos nas negociações agrícolas, principalmente do Ministério da Agricultura (MAPA). Por fim, pode-se concluir que o Acordo Agrícola permitiu que a agricultura fosse formalmente inserida nas discussões do GATT. Na Rodada de Doha, foram discutidos assuntos como os da área agrícola, de muito interesse para os países em desenvolvimento. Essas discussões permitiram que países em desenvolvimento possam reivindicar maior liberalização agrícola para seus produtos.
\end{abstract}

Palavras-Chave: Rodada do Uruguai. Rodada Doha. Negociações agrícolas.

\begin{abstract}
This paper aims to make reflections on the Uruguay and Doha Rounds and agricultural negotiations in the three pillars: market access, domestic support and export subsidies. For this, issues related to the restructuring of the world order in the post-Second World War period when the trade talks began to consolidate a process of
\end{abstract}


multilateral negotiations and will be presented a brief historic of the creation, appearance and evolution of the GATT. The informations are based on the Agricultural Agreement of the Uruguay Round and the Doha Declaration, as well as knowledge acquired in interviews with representatives of Brazilian actors involved in agricultural negotiations, especially the Brazilian Ministry of Agriculture (MAPA). Finally, it can be concluded that the Agricultural Agreement allowed agriculture to be formally inserted into the GATT discussions. In the Doha Round, were discussed issues such as the agricultural area of great interest for developing countries. These discussions have allowed developing countries can demand more agricultural liberalization for its products.

Keywords: Uruguay round. Doha Round. Agricultural Negotiations.

\begin{abstract}
Resumen
Este trabajo pretende hacer reflexiones sobre las rondas de Uruguay y Doha y las negociaciones agrícolas en los tres pilares: el acceso a los mercados, ayuda interna y subvenciones a la exportación. Para ello, se abordarán las cuestiones relacionadas con la reestructuración del orden mundial en el período post segunda guerra mundial, cuando las conversaciones sobre el comercio comenzó a consolidar un proceso de negociaciones multilaterales y se presentará una breve historia de la creación, el surgimiento y la evolución del GATT. La información está basada en el acuerdo sobre la agricultura de la ronda Uruguay y la declaración de Doha, así como los conocimientos adquiridos en las entrevistas con los representantes de los actores brasileños que participan en las negociaciones agrícolas, especialmente el ministerio de agricultura (MAPA). Por último, se puede concluir que el acuerdo sobre agricultura de la agricultura permitió que se inserte formalmente en las discusiones del GATT. En la ronda de Doha, se discutieron temas como la área agrícola de gran interés para los países en desarrollo. Estos debates han permitido a los países en desarrollo pueden reclamar una mayor liberalización de la agricultura para sus productos.
\end{abstract}

Palabras clave: Ronda de Uruguay. Ronda de Doha. Negociaciones Agrícolas.

\title{
Introdução
}

Ao final da II Guerra Mundial, houve a necessidade de se estabelecerem regras no campo comercial para evitar novos conflitos. Em 1947, com papel preponderante dos EUA, criou-se o primeiro fórum internacional para as discussões das questões vinculadas ao comércio entre os países, denominado de Acordo Geral de Tarifas e Comércio (GATT). Este fórum tinha como objetivo a redução das tarifas e das práticas protecionistas. As discussões pautavam-se na substituição progressiva de um protecionismo exagerado, dominante no mercado internacional, pela emergente ideologia defensora do livre comércio. As ideias fundamentais eram de que se deveria caminhar no sentido de consolidar um processo orgânico de negociações multilaterais em detrimento dos tradicionais acordos bilaterais entre os países.

Iniciavam-se, assim, as rodadas multilaterais de liberalização do comércio, nas quais grupos de países reuniam-se para negociar um conjunto de medidas, com o objetivo de liberalizar o comércio. Neste sentido, no contexto do GATT, desde 1947, ocorreram oito rodadas, sendo que somente na última delas, a Rodada do Uruguai, a questão agrícola começou a ser discutida com mais intensidade. Essa Rodada foi 
concluída em 1994 e nela ocorreu a fundação da Organização Mundial do Comércio (OMC).

A Organização Mundial do Comércio foi criada na Conferência de Marrakesh, de 1994, substituindo o GATT nas negociações internacionais. A OMC, em julho de 2008, possuía 153 membros, ou seja, ampla maioria dos países. Essa organização tem como objetivo regular o comércio internacional, eliminar barreiras econômicas e garantir a livre circulação de mercadorias, capitais e serviços, além de atuar como tribunal nos casos em que as partes não entram em acordo espontaneamente.

A OMC, tal como nas rodadas do GATT, realiza reuniões periódicas com o objetivo de promover a liberalização multilateral entre seus membros. Seu principal propósito é regulamentar o comércio e controlar as barreiras comerciais entre os países associados à organização e que nenhum produto receba tratamento diferente por causa da origem.

As tentativas de diminuir as diferenças econômicas entre os países ocorrem nas rodadas de negociação, em que os membros debatem o que precisa ser feito e tentam acordos, como na última rodada, iniciada em 2001, chamada de Rodada de Doha. Esta Rodada foi batizada de "Agenda de Desenvolvimento de Doha", visto que se trata de uma agenda de reuniões iniciada em 2001 com o objetivo de eliminar subsídios agrícolas e reduzir tarifas de importação. A Rodada de Doha tornou-se um ponto decisivo para o sistema comercial multilateral, exigindo do comércio mundial forte correção de rumos, principalmente do ponto de vista dos países em desenvolvimento, os quais têm seu comércio prejudicado por potências econômicas globais, como os Estados Unidos e a União Européia. No entanto, o impasse entre esses países e os países em desenvolvimento tende a enfraquecer o sistema multilateral de comércio como um todo.

No que se refere à agricultura, ressalta-se que esse assunto sempre foi complexo nas negociações de liberalização do comércio internacional, visto que durante quase quarenta anos, esse tema esteve sujeito a uma série de exceções, o que o deixou à margem da regulamentação existente. Neste sentido, este artigo busca resgatar os compromissos assumidos entre os países membros da OMC na Rodada do Uruguai e na Rodada de Doha com relação ao processo negociador nos três pilares das negociações agrícolas (acesso a mercados, apoio interno e subsídios às exportações).

\section{Reestruturação da ordem internacional}

A grande depressão mundial de 1930, que assolou principalmente a economia americana e se espalhou em seguida para a Europa, países da África, Ásia e América Latina, acabou causando grandes desequilíbrios internos e externos, os quais dificultaram as economias dos países abatidos pela crise. Nessa época, muitos países resolveram esse problema cortando suas relações comerciais com o resto do mundo e eliminando a possibilidade de qualquer desequilíbrio externo significativo. Houve também elevação das tarifas alfandegárias por parte de muitos países, diminuindo drasticamente o nível de comércio internacional. 
Esse movimento de redução das relações comerciais com o resto do mundo acabou por reduzir os ganhos do comércio, impôs custos elevados à economia global e fez com que o mundo demorasse a se recuperar da depressão, na qual, até 1939, vários países encontravam-se mergulhados. Neste sentido, começou a ocorrer o reconhecimento de que todos os países sairiam ganhando em um mundo com comércio internacional mais livre, uma vez que a cooperação internacional ajudaria cada país a preservar seu equilíbrio externo e a estabilidade financeira, sem sacrificar os objetivos da política econômica interna. Reconhecer esse fato foi o ponto de partida para o sistema monetário internacional que viria a vigorar no pós-guerra, o chamado acordo de Bretton-Woods (KRUGMAN; OBSTFELD, 2005).

Krugman e Obstfeld (2005) lembram que, mesmo com a continuidade da guerra, os representantes dos Estados aliados estavam inquietos com as necessidades econômicas mundiais após o fim do conflito. Levando em consideração o desastre econômico do período entre guerras que praticamente destruiu muitas economias, esses representantes queriam planejar um sistema monetário internacional que levasse ao pleno emprego, à estabilidade dos preços e que permitisse que os países alcançassem o equilíbrio externo sem ter de estabelecer restrições ao comércio internacional.

Em termos de comércio, as ideias principais eram de que se deveria caminhar no sentido de solidificar um processo orgânico de negociações multilaterais ao invés dos tradicionais acordos bilaterais entre os países. Sendo assim, dever-se-ia caminhar para a substituição progressiva de um protecionismo exagerado, dominante no mercado internacional, pela emergente ideologia defensora do livre comércio.

Neste sentido, ressalta-se que o grande desafio a ser enfrentado, no final da II Guerra Mundial, era a construção simultânea de uma paz duradoura e de um novo modelo de sociedade capitalista. Gonçalves et al. (1988) explicam que se buscava evitar uma instabilidade política e econômica que levasse ao avanço do socialismo, portanto, era necessário construir regras onde as forças de mercado pudessem atuar, evitando problemas futuros.

Cabe lembrar ainda que, de acordo com Vizentini (2007), em 1945, os Estados Unidos (EUA) tinham vantagens nunca vistas por nenhuma potência mundial, visto que dominavam os mares, tinham bases aéreas e navais, exércitos, bomba atômica e aviação estratégica com capacidade para alcançar grande parte do planeta. Os EUA passaram a regular e dominar os investimentos e o intercâmbio de mercadorias em escala planetária. Ressalta-se ainda que a hegemonia americana esteve presente também na diplomacia, com a criação da Organização das Nações Unidas (ONU), a qual serviu de instrumento jurídico, político e ideológico do internacionalismo indispensável à construção de um sistema mundial calcado no livre fluxo de mercadorias e de capitais.

Foi nesse momento histórico que representantes de 44 países se reuniram em Bretton Woods, New Hampshire, em 1944, para assinar o Acordo que deu origem ao Fundo Monetário Internacional (FMI), ao Banco Mundial e à Organização Internacional do Comércio (OIC). 
A instabilidade financeira, o desemprego e a desintegração econômica internacional que o mundo viveu no período entre guerras acabaram influenciando o acordo que criou o FMI. Este tem o propósito de ser uma instituição destinada a colaborar na manutenção do equilíbrio dos balanços de pagamentos, quando afetados por oscilações de caráter cíclico. Já o Banco Mundial tem a função de contribuir para a reconstrução da economia dos países destruídos pela guerra, incentivando-os a desenvolver políticas de crescimento de longo prazo. Além disso, ajuda antigos territórios colonizados a desenvolver e modernizar suas economias. Por sua vez, a Organização Internacional do Comércio (OIC) tinha como objetivo principal construir um sistema de comércio mundial com regras definidas, facilitando o funcionamento das forças de mercado e buscando redução às restrições do comércio (BARRAL, 2005).

Configurou-se, assim, um novo sistema financeiro internacional e, por trás disso, estava o propósito de criar condições para a globalização do capitalismo. Como nesse momento havia de um lado o bloco soviético, de outro os países de economia de mercado (o mundo capitalista), as instituições de Bretton Woods regeram apenas a economia destes últimos, até que o mundo se unificasse na década de 1990 (CERVO, 2008b).

A OIC foi idealizada e seus princípios passaram a constar na Carta de Havana, com a qual os países membros buscavam uma política de igualdade de tratamento para todos os países signatários, reduções tarifárias e eventual eliminação das restrições quantitativas ao comércio. No entanto, essa Carta precisava ser aprovada e ratificada pelos países que passariam a integrar a nova organização. Neste sentido, foi criado um acordo temporário que possibilitou lidar com as questões de tarifas e comércio até que a OIC fosse aprovada e ratificada e, assim, pudesse ser implementada.

Num ambiente de crença e de expectativas em relação à OIC, em 1947, em Genebra, 23 países assinaram o Acordo Geral de Tarifas e Comércio (GATT). Este tinha por objetivo "servir de fórum para a negociação de acordos, visando à redução de tarifas e outras barreiras não alfandegárias a fim de estimular o desenvolvimento do comércio internacional" (SATO, 2006, p. 131). Esse arranjo do GATT deveria ter caráter temporário até que a Carta de Havana fosse discutida e aprovada pelas partes contratantes. Em 1948, ela fora aprovada, mas sua implementação ficaria na dependência da ratificação por parte dos países que passassem a integrar a nova entidade. No entanto, o senado americano acabou rejeitando a Carta de Havana. Assim, a OIC foi idealizada, mas não foi efetivada, pois, como lembra Sato (2006), o fato de o congresso americano não ratificar a Carta acabou prejudicando a continuação dessa organização. Mas, no seu lugar, ficou o GATT que, por se tratar de um órgão executivo, não exigia a aprovação pelo Congresso (SATO, 2006). Alguns itens da Carta de Havana passaram a constar no Acordo Geral de Tarifas e Comércio (GATT) que, originalmente, era um acordo provisório, mas permaneceu até 1995, quando entrou em vigor a Organização Mundial do Comércio (OMC). 


\section{O Acordo Multilateral de Comércio Internacional}

Com relação ao GATT, cumpre ainda apresentar suas rodadas, dando ênfase principalmente à Rodada do Uruguai, que deu origem ao Acordo Agrícola, visto tratarse de um importante Acordo Multilateral que coordenou o comércio em nível mundial. O GATT era um acordo multilateral de comércio internacional que foi assinado em 1947, com o foco voltado ao livre comércio. Juntamente com o FMI e o Banco Mundial, acabou compondo a mais expressiva realização organizacional do Acordo de Bretton Woods. Cabe ressaltar que o referido acordo deu origem à atual estrutura do comércio internacional.

Salvatore (1998) afirma que o GATT é regido por três princípios básicos. O primeiro é o princípio do tratamento igual, ou seja, da não discriminação, em que os países membros comprometem-se a estender às outras partes contratantes qualquer vantagem, favor, imunidade ou privilégio concedido a qualquer outro país. O segundo é a eliminação de barreiras comerciais não tarifárias, tais como as cotas. O terceiro é a consulta entre as nações para a resolução de disputas comerciais no âmbito do GATT. As negociações entre os membros se davam em consecutivas reuniões, chamadas de rodadas de negociações que visavam à liberalização multilateral do comércio. Durante sua existência, o GATT contou com oito rodadas de negociações multilaterais de comércio.

Com relação a essas rodadas, cabe recordar que, no que se refere ao comércio agrícola, foco deste estudo, as quatro primeiras realizadas sob a égide do GATT - a original (1947) e as três seguintes, Annecy (1948), Torquay (1951) e Genebra (1956) pouco contribuíram para a liberalização do comércio agrícola. No entanto, isso não significa que não havia, desde o início, a consciência de que a situação em relação ao comércio agrícola era importante (MESQUITA, 2005).

Em 1958, foi organizado, sob o patrocínio do GATT, o Relatório Haberler que reconhecia a existência de barreiras que dificultavam as exportações de bens manufaturados e mesmo de excedentes de produtos primários das economias em processo de industrialização. Conforme descreve Sato (1998), esse documento sugeria às nações industrializadas a adoção de medidas que promovessem o acesso de produtos exportados aos seus mercados por países em desenvolvimento. O referido autor lembra ainda que se difundiu, nessa época, o célebre argumento de Raul Prebisch - sobre a existência de uma convergência secular no sentido da deterioração dos termos de troca dos países exportadores de bens primários -, o qual passou a encontrar eco inclusive no âmbito de prestigiosas instituições dos Estados Unidos.

A quinta rodada do GATT, a Rodada Dillon (1961), foi pautada na discussão de restabelecer o equilíbrio de direitos e de obrigações entre a Comunidade Européia e os demais membros. Ressalta-se que as reduções tarifárias acordadas nessa rodada não tiveram nenhum efeito significativo para os produtos agrícolas (MESQUITA, 2005).

A partir da Rodada Kennedy (1964), a sexta, as negociações passaram a envolver também as proteções não-tarifárias e a agricultura, mas de forma muito superficial, sendo que as primeiras rodadas multilaterais já ocorridas na época abordaram principalmente tarifas sobre produtos manufaturados (RODRIGUES; 
PAULA, 2008). Isso ocorreu porque, no início da década de 1960, os EUA começaram a enfrentar sucessivos déficits comerciais, nos quais o fluxo de investimentos norteamericanos para o exterior, somado ao déficit comercial, resultava em significativos déficits de balanço de pagamentos.

Com esse cenário, acabou sobrando espaço para que a agricultura passasse a desempenhar um papel central na nova rodada, pois os EUA tinham superávit agrícola, e as exportações adquiriam importância crescente para a sustentação da renda. A expectativa das autoridades norte-americanas, então, era de que a agricultura fosse liberalizada na nova rodada e, com isso, aumentassem as exportações que reduziriam os déficits comerciais americanos. Mas, ainda na Rodada de Tóquio, a sétima, os países membros deram maior atenção ao tratamento de barreiras tarifárias e não tarifárias sobre produtos industrializados.

Desse modo, como explica Mesquita (2005), ao final de sete rodadas de negociações comerciais, ainda não fora possível adotar disciplinas eficazes para a agricultura. Ao contrário, as distorções tornaram-se mais marcantes com a conformação da Política Agrícola Comum (PAC), com seu forte viés protecionista que tornou a Comunidade Econômica Européia em um amplo exportador dos principais produtos agrícolas. O referido autor ressalta que as regras aplicáveis ao comércio de produtos agrícolas eram praticamente inexpressivas. Desde o início do GATT, foi difícil submeter o comércio de produtos agrícolas a regras efetivas, sendo que, durante a sua existência, a agricultura resistiu a todas as tentativas de liberalização e de disciplinamento. De acordo com Mesquita (2005, p.45), “durante as sete primeiras rodadas de negociações comerciais multilaterais, não houve um debate mais apurado sobre o protecionismo agrícola".

Cabe lembrar que os constantes problemas para estabelecer disciplinas agrícolas nas Rodadas Dillon, Kennedy e Tóquio acabaram gerando pessimismo em relação não somente à inserção da agricultura às regras do GATT, mas quanto às perspectivas do próprio sistema de comércio multilateral. A agenda do GATT, até a Rodada Tóquio, era substancialmente uma agenda negativa, sem disciplinamento e discussões mais profundas para o setor agrícola. Mas foi a partir da Rodada do Uruguai, na década de 1980, que se caminhou na direção de uma agenda positiva que implicou a regulação de políticas domésticas dos governos nacionais que tivessem efeitos sobre o comércio internacional (GONÇALVES et al., 1998).

A Rodada do Uruguai, realizada de 1986 a 1994, com a participação de 123 países, diferenciou-se das anteriores, por ter sido a mais completa e mais ousada rodada já realizada no GATT, sendo que foi nesse período que, inclusive, começou a discussão mais intensa sobre a liberalização agrícola. Conforme já ressaltado, por longo período das negociações do GATT, as discussões sobre questões agrícolas foram praticamente excluídas de sua agenda, devido à pressão dos países desenvolvidos que protegiam seus mercados e subsidiavam fortemente a agricultura. Destaca-se ainda que, pelo fato de ser um setor tão relevante e também tão sensível, o comércio internacional agrícola esteve sempre sujeito a diversas exceções, ficando ausente das regras multilaterais que disciplinam o comércio internacional no que se refere à agricultura. 
No início dos anos 80, o contexto vivenciado na Europa favoreceu a redução do apoio agrícola, pois os dois choques do petróleo levaram a grandes déficits fiscais, agravando a pressão sobre os orçamentos dos governos, fazendo com que os subsídios agrícolas significassem um ônus excessivo para os tesouros europeus. Esse quadro permitiu que, na pauta da reunião em Punta Del Leste - onde foi lançada a Rodada do Uruguai - fossem incluídos os temas agrícolas.

Desse modo, estabeleceu-se na Rodada do Uruguai um Acordo Agrícola visando a regulamentação da agricultura. Esse acordo trouxe diversas regras de comércio para a agricultura. As concessões e compromissos assumidos tornaram-se o marco jurídico-institucional para o projeto de reforma de longo prazo do comércio na agricultura.

Os resultados da Rodada do Uruguai de negociações multilaterais se concentraram em uma ata final, onde constam 16 artigos e quatro anexos. Mancini (2008) destaca que, até a Rodada do Uruguai, a posição brasileira no GATT era fortemente defensiva, uma vez que seu modelo de desenvolvimento era baseado no mercado interno. Embora o governo tivesse interesses agrícolas, não havia um esforço de sua parte para a defesa de uma agenda nessa área, explica a autora citada.

O Acordo Agrícola trouxe uma série de regulamentações para a agricultura como será mais bem abordado na sequência deste estudo - dentre as quais está a própria submissão do setor às normas do GATT. Nesse momento, foram definidas três grandes modalidades das negociações agrícolas: acesso a mercados, apoio doméstico e subsídios à exportação (ARAÚJO; JANK, 2003).

\section{A Rodada do Uruguai e o Acordo Agrícola}

As discussões neste item têm como referência, além do Acordo Agrícola, comentários sobre os artigos desse acordo, os quais foram feitos pelo funcionário do MAPA que foi entrevistado pela autora do trabalho em janeiro de 2011 em Brasília, além de Comunicação pessoal recebida em 01 de fevereiro de 2011 por correio eletrônico.

Cabe lembrar que as negociações agrícolas se deram em tres pilares: acesso a mercados, apoio doméstico e subsídios às exportações. No que se refere ao Acesso a Mercados, as negociações agrícolas basearam-se na eliminação de barreiras nãotarifárias, através do mecanismo de "tarificação", e na consolidação e redução dos níveis tarifários. O item de Acesso a Mercados, artigo $4^{\circ}$ do Acordo Agrícola da Rodada do Uruguai, refere-se ao grau de abertura de determinado mercado aos produtos estrangeiros. Relaciona-se ainda aos instrumentos e disciplinas que afetam a entrada de produtos de um país qualquer em outros países, tais como as restrições e/ou limitações à importação, com influência direta na competição entre produtos importados e seus similares domésticos. O Acordo Agrícola postulava que o Acesso a Mercados deveria ser ampliado através de redução nas barreiras e nas restrições comerciais. 
Assim, nenhum país poderá fazer uso de barreiras não-tarifárias para impedir o acesso de produtos de outros países em seu mercado doméstico. A única forma de restringir a entrada de produtos passou a ser a tarifa, logo, o limite da proteção passa a ser o nível da tarifa consolidada, isto é, registrada na OMC. Araújo e Jank (2003) lembram que as restrições de acesso, antes da Rodada do Uruguai, davam-se de diversas formas, tais como restrições quantitativas, preços mínimos de importação, direitos variáveis sobre importações, licenças de importação discricionárias e restrições voluntárias à exportação. Desde então os países desenvolvidos passaram a fazer mais uso das barreiras técnicas e sanitárias.

A eliminação de todas as barreiras não tarifárias se daria pela sua transformação em um equivalente tarifário, isto é, pelo cálculo de uma tarifa que desse proteção equivalente. A metodologia utilizada era fazer com que o equivalente tarifário fosse estimado pela diferença no período base, (1986-1988) entre o preço vigente no mercado interno do produto protegido e o seu preço externo de referência. Isso acabou resultando em tarifas muito elevadas, os chamados "picos tarifários".

Então, no intuito de resolver problemas de tarifas muito elevadas - resultado do processo de "tarificação" -, os países que fizeram "tarificação" deveriam se comprometer a assegurar um determinado acesso aos seus mercados através de cotas tarifárias, garantindo "acesso mínimo" ou "acesso corrente". De acordo com o Acordo Agrícola, o "acesso corrente" não pôde ser inferior a 3\% do consumo interno do país, se tal ocorresse, ele deveria garantir um "acesso mínimo", isto é, que no mínimo 3\% (calculado entre os anos de 1986 e 1988) do seu consumo interno fosse atendido por importações de outros países. Além disso, o país se comprometia a ampliar esse "acesso mínimo" em 5\%, até o ano 2000 e, até 2004, para os países em desenvolvimento. Abaixo segue figura 1 ilustrativa dos instrumentos de Acesso a Mercado da Rodada do Uruguai.

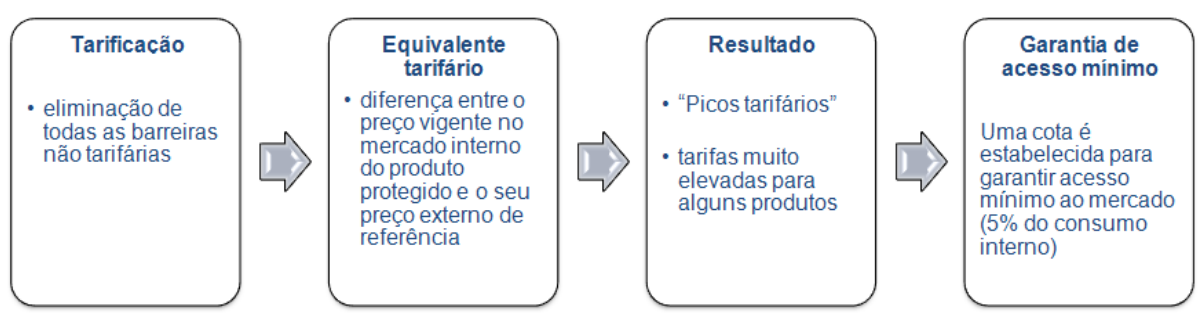

Figura 1 - Acesso a Mercado - Rodada do Uruguai Fonte: elaboração própria.

Carmona (2011) ressalta que foi dada alternativa para os países em desenvolvimento de consolidar tetos tarifários ao invés das tarifas praticadas em setembro de 1986. Por esse motivo, poucos países em desenvolvimento recorreram ao 
mecanismo da "tarificação", já que tiveram liberdade para fixar suas tarifas em patamares bem confortáveis.

Ficou acordado ainda que, durante o período de implementação do Acordo Agrícola, fosse feita uma redução média de pelo menos $36 \%$ nas tarifas agrícolas, por parte dos países desenvolvidos, com uma redução mínima de $15 \%$ por linha tarifária. Vale lembrar que, para os países em desenvolvimento, essas reduções foram de dois terços, ou seja, $24 \%$ e $10 \%$, respectivamente. Para os países desenvolvidos, as reduções aplicaram-se sobre as tarifas vigentes em setembro de 1986 ou sobre os equivalentes tarifários resultante da tarificação (ACORDO AGRÍCOLA, 1996).

No que se refere ao tipo de tarifas, existem duas: a aplicada e a consolidada. A tarifa aplicada é a imposta efetivamente sobre as importações. Pode ser menor que a tarifa consolidada na OMC, porém não pode ser maior, conforme acordado na Rodada do Uruguai. Por sua vez, a tarifa consolidada, que é a negociada na OMC, é fixada como limite máximo ou teto tarifário dentro de uma negociação comercial nessa organização. Contudo, a tarifa aplicada não pode ultrapassar a tarifa consolidada (GLOSSÁRIO ÍCONE, 2011).

A “água” na tarifa é a diferença entre a tarifa aplicada e aquela necessária para gerar comércio, ou seja, diferença entre a tarifa aplicada e a consolidada. Jakobsen (2008) explica que manter essa diferença entre as tarifas permite aos países em desenvolvimento elevá-las até o limite do percentual consolidado num momento de ameaça competitiva inesperada. Assim, essa diferença entre as tarifas tornou-se um mecanismo macroeconômico para os países em desenvolvimento.

Por sua vez, o pilar de Apoio Doméstico encontra-se descrito no artigo 6 do Acordo Agrícola da Rodada do Uruguai e refere-se às medidas adotadas pelos governos que têm por finalidade conferir um auxílio-proteção ao produtor nacional, por meio de subsídios ao preço de mercado ou de pagamentos diretos do governo. Cabe ressaltar que algumas políticas de apoio doméstico, como suporte de preço ou produções subsidiadas, acabam tendo o efeito de estimular a produção. $\mathrm{Ou}$ isso reduz as importações ou irão ocorrer exportações subsidiadas, o que acarreta em redução dos preços internacionais. O acordo sobre agricultura definiu dois tipos de medidas de apoio: as que estimulam diretamente a produção, e as que não têm efeito direto sobre ela. Desse modo, agrupou as políticas de apoio doméstico em três tipos: Caixa Verde, Caixa Amarela e Caixa Azul. Os subsídios são classificados de acordo com seu grau de distorção ao comércio e prevê medidas de uso exclusivo para os países em desenvolvimento (CARTA DE GENEBRA, 2002).

Na Caixa Verde, estão as medidas com impactos mínimos ao comércio e que podem ser usadas de forma livre, pois esta é composta por políticas de efeito nulo ou mínimo sobre a produção e, portanto, não sujeitas a compromissos de redução. Essas políticas incluem serviços governamentais, tais como pesquisa, defesa e inspeção sanitárias, infraestrutura "da porteira para fora" e segurança alimentar. Além disso, incluem pagamentos feitos diretamente aos produtores, desde que não estimulem a produção, tais como certas formas de suporte direto à renda, assistência para ajudar os produtores a reestruturar sua agricultura, além de pagamentos sob programas ambientais e de desenvolvimento regional. 
Por sua vez, a Caixa Azul contempla instrumentos ligados a controle de oferta e não estão sujeitos a compromissos de controle e redução da produção. Nesta caixa, a qual requer limitação na produção, além de certos programas governamentais para fomentar o desenvolvimento rural em países em desenvolvimento, foram permitidos pagamentos aos produtores.

Por fim, as políticas que fazem parte da Caixa Amarela são todas as governamentais que resultem em transferências orçamentárias ou pagamentos que o governo ou suas agências fazem em favor dos agricultores. Nestas estão incluídas apoios a preços, pagamentos diretos não-isentos de compromissos de redução, ou quaisquer outros subsídios não-isentos (CARTA DE GENEBRA, 2002). Os países desenvolvidos acordaram reduzir os números das políticas da Caixa Amarela em 20\% em seis anos, iniciando em 1995. Países em desenvolvimento concordaram em cortar $13 \%$ dessas mesmas políticas em 10 anos. Observa-se que os países de menor desenvolvimento relativo não tiveram que se comprometer com qualquer corte.

Cabe ressaltar que as políticas da Caixa Amarela, que têm efeitos diretos sobre a produção, foram reduzidas e limitadas durante a Rodada do Uruguai. Carmona (2011) explica que os membros da OMC calcularam quanto de suporte desse tipo de política foi concedido para o setor agrícola entre 1986 a 1988, usando a Medida Geral de Apoio (MGA) ou AMS- sigla em inglês. A AMS refere-se a um índice que mede o valor monetário da extensão do apoio governamental a um setor. A AMS, de acordo com a definição constante no Acordo sobre Agricultura da OMC, inclui desembolsos tanto orçamentários quanto de transferências de receita dos consumidores aos produtores, como resultado de políticas que distorcem os preços de mercado (DICIONÁRIO DE TERMOS DE COMÉRCIO, 2011).

O cálculo do AMS se dá quando o governo garante um preço mínimo aos produtores, ou ele paga a diferença entre o preço mínimo e o preço de mercado ao produtor, ou ele compra a produção pelo preço mínimo estabelecido. No primeiro caso, o subsídio considerado é o valor total desembolsado pelo governo. No segundo caso, calcula-se a diferença entre o preço mínimo garantido e o preço de referência multiplicado pela produção atendida. O preço de referência é o preço de paridade de importação ou de exportação, dependendo do produto, no período entre 1986 e 1988.

Cada país calculou o subsídio distorcivo (Caixa Amarela) concedido a cada um dos seus produtos entre 1986 e 1988. Para aqueles produtos cujo apoio ficou acima de $5 \%$ do valor da produção, o valor do subsídio entrou no cálculo do AMS. No caso dos países em desenvolvimento, o percentual foi de $10 \%$. Esse valor é o chamado de minimis. Quando os subsídios distorcivos estão abaixo deste limite, estes não estão sujeitos aos compromissos de redução da Caixa Amarela. Atualmente esta caixa é uma das questões agrícolas em negociação nas discussões de Rodada de Doha, explica Carmona (2011).

Os países desenvolvidos acordaram reduzir o AMS em $20 \%$ em seis anos, iniciando em 1995. Países em desenvolvimento concordaram em cortar $13 \%$ em 10 anos. Os países de menor desenvolvimento relativo não tiveram que se comprometer com qualquer corte. 
No que se refere aos Subsídios às Exportações, o Acordo Agrícola da Rodada do Uruguai acabou por proibir os países membros de dar subsídios vinculados à exportação, a menos que os subsídios estejam especificados na sua lista de compromissos. Subsídios à exportação são aqueles subsídios diretos a produtos voltados à exportação (GLOSSÁRIO ICONE, 2011).

O subsídio à exportação pode se dar através da garantia de um preço mínimo nas exportações, pelo qual o governo reembolsa ao produtor a diferença entre o preço exportado e o preço mínimo de garantia. $\mathrm{O}$ acordo da Rodada do Uruguai requer que os membros da OMC cortem tanto os valores monetários gastos quanto as quantidades exportadas que recebem subsídios.

Tomando as médias de 1998-90 como base, países em desenvolvimento concordaram em reduzir o valor das exportações em $36 \%$, ao longo de seis anos, começando em 1995, e os países em desenvolvimento, 24\% em dez anos. Os países desenvolvidos também concordaram em reduzir as quantidades exportadas com subsídios em $21 \%$, no período de seis anos, e os países em desenvolvimento em $14 \%$, no período de dez anos. $\mathrm{O}$ artigo $9^{\circ}$ do parágrafo do Acordo Agrícola faz referência a parágrafos relativos à definição do que é um subsídio à exportação. Esses subsídios à exportação estão sujeitos aos compromissos de redução assumidos em virtude do acordo da Rodada do Uruguai.

$\mathrm{O}$ artigo $5^{\circ}$ do Acordo Agrícola da Rodada do Uruguai trata da Salvaguarda Especial (SSG). Esse acordo permite aos países que procederam a Tarificação o dispositivo da Salvaguarda Especial que admite impor uma sobretaxa à importação de determinado produto, nas seguintes condições: o volume de importação do produto objeto do processo de "tarificação" aumenta excessivamente, ou o preço de importação do produto cai excessivamente em relação à média de referência do período 1986/88. Mas o acordo diz que a Salvaguarda Especial só pode ser acionada no comércio extracota, no caso de cotas tarifárias.

O Acordo Agrícola reconhece ainda o tratamento diferenciado e mais favorável a países membros em desenvolvimento. Esses países tiveram flexibilidade para implementar os compromissos de redução ao longo de um período de até 10 anos. Não se exigiu dos países membros de menor desenvolvimento relativo que assumam compromissos de redução.

Embora o objetivo fosse o de se fazer uma "tarificação" ampla, por questões políticas, foi negociada uma flexibilização em sua aplicação, desde que atendidos certos critérios: o produto beneficiado não poderia ser objeto de subsídios às exportações no país requerente; o produto deveria estar sujeito a políticas de controle de produção e as importações, no período base, deveriam ser inferiores a 3\% do consumo interno. Carmona (2011) explica que essa flexibilização (prevista no Anexo V do Acordo Agrícola da Rodada do Uruguai) atendeu a interesses muito particulares do Japão e da Coréia do Sul, os quais tinham dificuldade para eliminar, de imediato, as restrições às importações de arroz.

O Acordo Agrícola, em seu artigo $13^{\circ}$, introduziu ainda a chamada Cláusula de Paz, ou de devida moderação, pela qual prevê que, durante o período de 
implementação do Acordo, até dezembro de 2003, as medidas de apoio doméstico adotadas pelos membros da OMC temporariamente não poderiam ser acionadas com base no Acordo sobre Subsídios e Medidas Compensatórias da OMC. Desse modo, tais medidas estavam isentas de ações baseadas na anulação e limitação de benefícios e concessões tarifárias, dentro do Órgão de Solução de Controvérsias. Essa Cláusula de Paz estava em vigor desde $1 .^{\circ}$ de janeiro de 1995, com duração prevista de 9 anos, chegando a seu termo final no fim de dezembro de 2003. Cabe lembrar que, de acordo com Carmona (2011), essa cláusula foi uma exigência dos EUA e da UE para a conclusão da Rodada do Uruguai, porque eles temiam uma enxurrada de contenciosos logo após a sua conclusão, fato que não se confirmou.

\section{A Organização Mundial do Comércio (OMC)}

Na década de 1980 para 1990, também houve grandes transformações no cenário internacional, como o fim da Guerra Fria que se concretizou através de fatos, como a queda do Muro de Berlim (1989) e a dissolução da URSS (1991). Esses fatos revelam o triunfo do eixo capitalista e da globalização, e esse período foi proclamado pelo "presidente Bush" como de 'Nova Ordem Mundial', anunciada como a era da paz duradoura, prosperidade e democracia" (VIZENTINI, 2005). Com as ideias do liberalismo econômico, logo começou a ocorrer à percepção de uma importância maior das regras de comércio internacional. Neste sentido, buscou-se reforçar essas ideias através da criação de uma instituição que se ocupasse das normas que regem o comércio entre os países, em nível mundial, sendo esta uma organização para liberar o comércio, além de ser um foro para que os governos negociem acordos comerciais e ainda busquem resolver suas diferenças nessa área.

Desse modo, em 1995, no final da Rodada do Uruguai, passou a funcionar a Organização Mundial do Comércio (OMC), criada pelo acordo de Marraqueche, assinado em Marrocos, em 1994, e com sede em Genebra, na Suíça. O acordo que cria a OMC contempla em sua estrutura Conferências Ministeriais que se realizam uma vez a cada dois anos.

A criação da OMC completou a estrutura do tripé (FMI, BIRD e OMC) que fora planejado em Bretton Woods (DI SENA JR, 2006). Esta é uma organização que provê fundamentos legais e institucionais ao sistema de comércio multilateral, constituindo-se, na prática, num foro onde se desenvolvem os processos de regulamentação do comércio multilateral (FORSCHETE, 2001). A criação da OMC, em 1995, também significou a maior reforma do comércio internacional desde a II Guerra Mundial, constituindo-se em uma forma atualizada da OIC que foi idealizada, mas não implementada em 1948.

A OMC possuía 159 membros em 2 de março de 2013. Entre seus princípios básicos estão: o princípio da nação mais favorecida, ou seja, tratamento igual para todos os membros da OMC, sem discriminação; e o princípio do tratamento nacional que diz respeito à não discriminação entre os produtos nacionais de um Estado-membro da OMC e dos demais membros, significando que as mercadorias e serviços nacionais e importados devem ter um tratamento igual. 
As funções da OMC evoluiu na última década. Esta passou a ser um foro de negociações e supervisão das regras do comércio mundial e também atua como tribunal diplomático-jurídico de conflitos comerciais, no âmbito de seu mecanismo de solução de controvérsias. Com relação a seus textos jurídicos, estes envolvem o chamado princípio do compromisso único (single undertaking), isto é, os membros não podem selecionar isoladamente acordos, pois eles são vinculados entre si num só conjunto. Isso implica que, enquanto não houver definição para algum dos pontos negociados, nada estará acordado de forma definitiva. Nos acordos plurilaterais da OMC, não se aplica esse princípio. No âmbito da OMC, os acordos plurilaterais são aqueles que têm como característica principal a adesão facultativa, ou seja, são válidos somente para seus signatários. Como exemplos, destacam-se o Acordo sobre Compras Governamentais, o Acordo sobre o Comércio de Aeronaves Civis e o Acordo sobre Produtos de Tecnologia da Informação (ICONE, 2011).

A primeira conferência ministerial da Organização Mundial do Comércio realizou-se em Cingapura, em 1996, com a participação de 128 membros, com o propósito de elaborar e rever regras vigentes no comércio internacional. Os pontos discutidos foram o acordo de informática e tecnologia, os subsídios agrícolas e a cláusula social, sendo que, desses tópicos de discussão, o acordo de informática e tecnologia levou a maior parte das discussões, constituindo-se vantagem para os países desenvolvidos (GRIECO, 2001).

A segunda conferência ministerial realizou-se em Genebra, em 1998. Nesta, houve o estudo de medidas para acelerar a implementação do Plano de Ação para os Países menos desenvolvidos. No entanto, o debate das negociações foi mais intenso sobre telecomunicações e serviços financeiros e sobre a implementação do Acordo de Informação Tecnológica.

A terceira conferência realizou-se em Seattle, em 1999. As negociações agrícolas, a partir daí, ocuparam grande parte da agenda da OMC até o ano 2000. Nesse período, convergiram interesses dos EUA, do Grupo de Cairns e, especialmente, do Brasil (GRIECO, 2001). Essa conferência de Seattle pretendia lançar uma nova rodada de negociações da OMC, mas acabou fracassando devido a grandes divergências entre os países desenvolvidos e os em desenvolvimento. A conferência de Seattle passou a ser um divisor de águas para uma postura mais crítica dos países em desenvolvimento.

A quarta conferência ministerial, de novembro de 2001 , foi realizada em Doha, no Catar. Nesta foi feito o lançamento da rodada de negociações multilaterais, a Rodada Doha para o desenvolvimento, representando um marco na história da OMC.

Na Conferência Ministerial que aconteceu em Doha, em novembro de 2001, deu-se início a uma nova Rodada de Negociações chamada "Agenda para o desenvolvimento" e foram incluídos temas importantes e de grande interesse para os países em desenvolvimento, tais como agricultura, serviços, Acesso a Mercados, novas regras antidumping, subsídios e propriedade intelectual. Esta nova rodada de negociações incluiu, ainda, novos temas, como investimentos, concorrência, compras governamentais e meio ambiente. Nessa rodada, permaneceram as divergências entre os dois grupos de interesses - os países desenvolvidos e os países em desenvolvimento. 
Na Rodada de Doha, estavam em discussão temas de grande interesse para o Brasil, como agricultura, serviços, acesso a mercados com nova etapa de redução tarifária para produtos industriais, aprofundamento de regras sobre antidumping, subsídios, acordos regionais e propriedade intelectual, além de novos temas, como investimentos, concorrência, transparência em compras governamentais, facilitação de comércio e comércio eletrônico e meio ambiente (CARTA DE GENEBRA, 2002).

A Rodada de Doha deu continuidade e tentou aprofundar o processo de reformulação do setor agrícola, iniciado na Rodada do Uruguai, com vistas à plena integração do setor nas disciplinas multilaterais de comércio. Conforme já ressaltado, foi na Rodada do Uruguai, com a assinatura do Acordo Agrícola, que se deram os primeiros passos de liberalização do setor, através de um tripé de negociações: aumentar o acesso a mercados, diminuir os níveis de apoio doméstico e disciplinar as formas de competição nas exportações. De acordo com a Carta de Genebra, o próprio Acordo apresentava em seu bojo, no artigo 20, mecanismo que presumia a continuidade das negociações no intuito de aprofundar o processo de reforma da agricultura, mas, em Doha, o Acordo Agrícola acabou adquirindo maior consistência e ambição em seu mandato (CARTA DE GENEBRA, 2002).

Cabe ressaltar que, na Declaração de Doha, os ministros se comprometeram com negociações abrangentes, destinadas ao aumento substancial do acesso a mercados e a reduções, tudo isso com o objetivo de eliminar gradualmente todas as formas de subsídios à exportação e apoios internos que distorcem o comércio. O mandato previu que os dispositivos de tratamento especial e diferenciado para países em desenvolvimento fossem incorporados nas listas de concessões, e que as preocupações de natureza não-comercial fossem levadas em consideração.

A Declaração Ministerial de Doha propunha uma agenda bastante abrangente, pois indicava que esta seria uma Agenda para o Desenvolvimento, e os interesses dos países mais pobres seriam levados em consideração. No entanto, muitas dessas boas intenções arrefeceram nos anos seguintes, no momento de discutir os textos a serem negociados.

O programa de trabalho iniciado em Doha dá prosseguimento e aprofunda o processo de reforma do setor agrícola, iniciado desde a Rodada do Uruguai, com vistas à plena integração do setor. Na sequência, são apresentadas informações sobre os três pilares das negociações agrícolas da Rodada Doha da OMC.

\section{A Rodada Doha e os pontos do possível acordo}

Nesta seção, pretende-se trazer informações sobre as negociações agrícolas e os três pilares que as sustentam na Rodada Doha da OMC: o Acesso a Mercados, apoio doméstico e subsídios à exportação discutidos. As informações contidas nesta seção têm como base o documento de modalidades da Rodada de Doha, aprovado em 8 de dezembro de 2008, assim como conhecimentos adquiridos nas entrevistas com representantes dos atores brasileiros envolvidos nas negociações agrícolas. Cumpre explicar que o documento de modalidades contém quase todos os elementos de uma 
eventual conclusão da Rodada de Doha. As discussões neste item também têm como referência comentários sobre os artigos do Acordo Agrícola da Rodada do Uruguai feitos pelo funcionário Coordenador Geral de Assuntos Multilaterais do MAPA e entrevistado pela autora do trabalho.

Quanto às discussões sobre acesso a mercado, estas continuam sendo bastante complexas na Rodada de Doha. Uma das novidades dessa rodada é que os países em desenvolvimento terão de reduzir suas tarifas e não apenas consolidá-las nos níveis que consideram necessários.

No que se refere à redução tarifária, esta havia sido acordada na Rodada do Uruguai, conforme já explicado anteriormente, onde ficou estabelecido que, para os países desenvolvidos, a regra seria redução média de pelo menos $36 \%$ nas tarifas agrícolas, com um mínimo de $15 \%$ por linha tarifária. No entanto, como resultado da Rodada do Uruguai, ocorreram os chamados picos tarifários, ou seja, tarifas bem acima da média, e as escaladas tarifárias que são as tarifas maiores para produtos mais elaborados. Isso ocorreu porque os países cortaram menos as tarifas maiores, para produtos mais sensíveis, e mais as tarifas menores, para produtos não sensíveis. Com isso, as tarifas mais altas ficaram mais distantes das tarifas mais baixas (CARMONA, 2011).

Para tentar minimizar o problema na Rodada de Doha, foram utilizadas fórmulas por bandas que prevêem que, quanto maior a tarifa, maior o corte tarifário. Os países desenvolvidos deverão atingir um corte médio de 54\%. Se a fórmula não levar a esse número, esse grupo terá que fazer cortes extras para atingi-lo. No caso dos países em desenvolvimento, se a fórmula levar a um corte médio maior que $36 \%$, estes poderão fazer cortes menores que a fórmula para atingir o resultado de $36 \%$. Com relação aos países recém-acedidos à $\mathrm{OMC}$, estes terão tratamento diferenciado (mais brando) (MODALIDADES AGRICULTURA, 2008, parágrafos 61 a 65). Abaixo segue figura 2 explicativa da redução tarifária na Rodada do Uruguai e na Rodada de Doha.

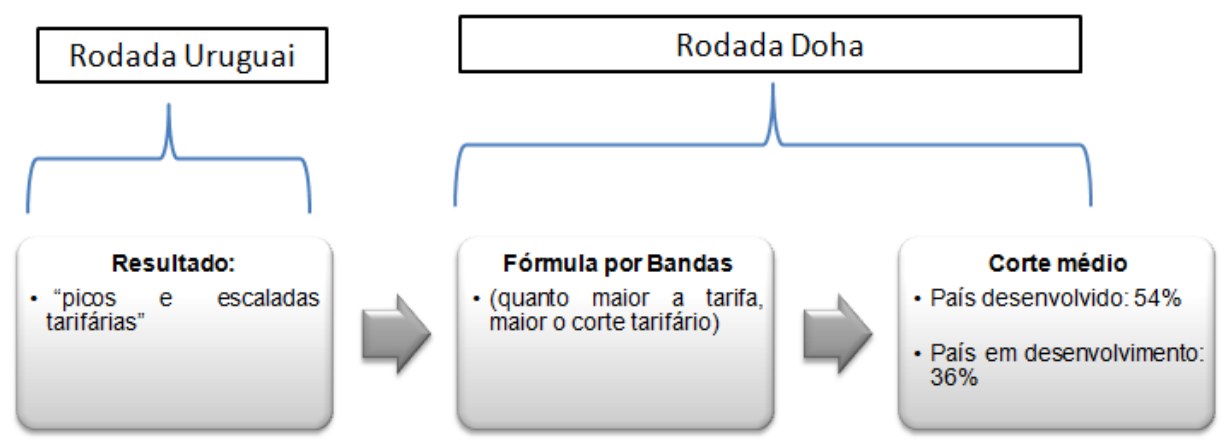

Figura 2 - Redução tarifária - Rodada do Uruguai e Rodada de Doha Fonte: elaboração própria. 
O corte tarifário da Rodada de Doha será feito de acordo com o tamanho da tarifa. Desse modo, foi necessário criar uma metodologia para converter as tarifas não ad valorem (específicas) em seus equivalentes ad valorem (porcentagem). A tarifa ad valorem é a cobrada em bases percentuais sobre o valor da mercadoria. Por exemplo, uma tarifa de 5\% significa que o imposto de importação equivale a $5 \%$ do valor estimado da mercadoria. Já, a tarifa específica é a fixada em termos de encargos monetários específicos por unidade ou quantidade do bem importado. Por exemplo, US\$100,00 por tonelada métrica de determinado bem (DICIONÁRIO DE TERMOS DE COMÉRCIO, 2003, p. 48).

Quanto às Cotas Tarifárias, na Rodada de Doha, foram criadas regras especiais para os produtos sensíveis, mas os produtos considerados sensíveis na Rodada do Uruguai continuam sendo considerados sensíveis na Rodada de Doha. A regra é que países desenvolvidos podem selecionar até $4 \%$ das suas linhas tarifárias como produtos sensíveis, sendo que para esses produtos os países têm o direito de cortar tarifa menos que a fórmula (MODALIDADES AGRICULTURA, 2008, parágrafo 71). Estes produtos são aqueles que possuem grande sensibilidade aos produtos importados que são passíveis de prejudicar sua produção e comercialização, normalmente são produtos com escala pequena de produção. Pelo lado do exportador, podem ser definidos como aqueles que respondem por uma grande porcentagem das exportações totais de um país qualquer e que sofrem altas barreiras de importação por parte de outros países. Já, pelo lado do produtor doméstico, são aqueles em que o país importador é pouco competitivo na sua produção e, portanto, a livre entrada desse produto importado pode causar prejuízos e tornar desinteressante a sua produção doméstica (GLOSSÁRIO ICONE, 2011). Isso significa que, quanto maior o desvio em relação à fórmula, maior a expansão da cota.

Carmona (2011) comenta que um dos pontos ainda não acordados na Rodada Doha, e que é de grande divergência, é a questão se será ou não permitida a designação de produtos que hoje não têm cota tarifária como produto sensível.

No documento de modalidades, existem regras acordadas para cortes nas tarifas extracotas. A regra geral é que, para os países desenvolvidos, todas estas tarifas devem ser cortadas em $50 \%$ ou reduzidas a $10 \%$, o que resultar em menor redução de tarifas (MODALIDADES AGRICULTURA, 2008, parágrafo 109). Além disso, na Rodada de Doha, existem alguns temas, como escalada tarifária, produtos tropicais, erosão de preferências, simplificação das tarifas, que não haviam sido tratados na Rodada do Uruguai. Sobre cada um deles são feitos comentários a seguir.

Para a Rodada de Doha, foi definida uma lista de produtos que estará sujeita a cortes maiores com o objetivo de diminuir a escalada tarifária. Nessa rodada, houve uma demanda criada pelos países em desenvolvimento no sentido de uma liberalização maior que a prevista na fórmula geral para os produtos tropicais. Os países em desenvolvimento têm grande interesse em exportar estes produtos.

No que se refere à Erosão de Preferência, cabe ressaltar que existem países que há muitos anos têm se beneficiado de preferências tarifárias concedidas por países desenvolvidos. Segundo muitos países, o problema disso é que as reduções tarifárias, 
resultado da Rodada de Doha, trariam prejuízos por reduzir esse benefício. Esse efeito é conhecido como Erosão de Preferência.

Como parte do tratamento especial e diferenciado concedido a países em desenvolvimento, acordou-se que estes terão o direito de designar certo número de linhas tarifárias como produtos especiais, os quais sofrerão corte tarifário menor que a regra geral, inclusive com parte das linhas, sem sofrer corte algum. Os produtos especiais é a relação de produtos definida pelo Conselho Nacional de Segurança Alimentar e Nutricional - CONSEA, da Presidência da República, já excluídos os produtos tipicamente de exportação do Brasil: arroz, feijão, alho, cebola, leite, mandioca, milho, tomate e trigo. (MDA, 2007)

A diferença em relação aos produtos sensíveis é que não haverá compensação por isso. Cabe explicar que produtos especiais são produtos agrícolas que terão um tratamento diferenciado, ou seja, ficam sujeitos a menores compromissos de redução tarifária, mas não ficam sujeitos a compromissos de extensão de quotas tarifárias. Estes produtos são considerados de grande importância pelos países em desenvolvimento para a segurança alimentar e para o desenvolvimento rural. Na sequência, segue esquema explicativo que apresenta os pontos que não haviam sido tratados na Rodada do Uruguai (RU) e estão presentes no documento de modalidades da Rodada de Doha:

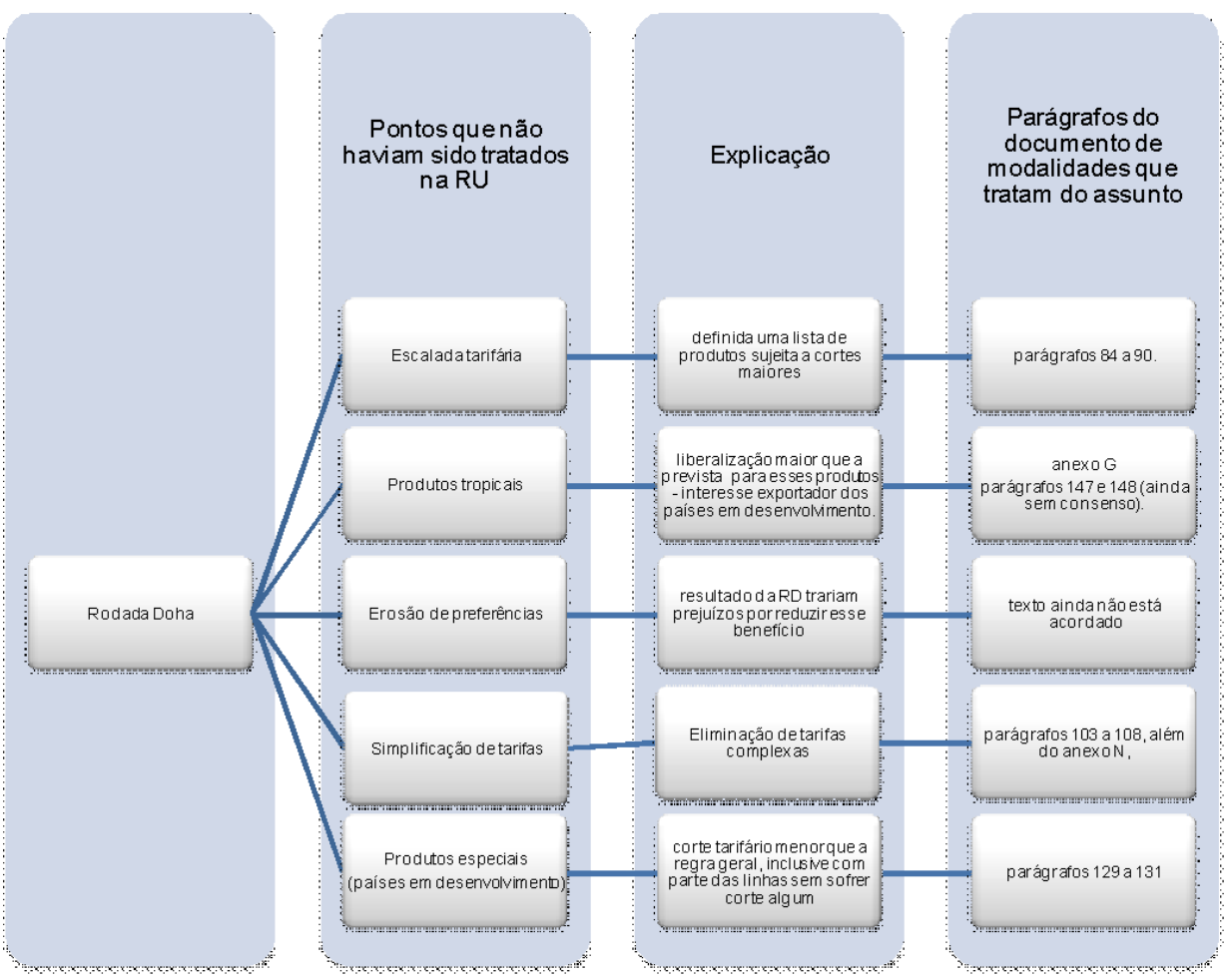

Figura 3 - Pontos que não haviam sido tratados na Rodada do Uruguai Fonte: elaboração própria. 
No que se refere ao pilar de Apoio Doméstico, o documento de modalidades da Rodada de Doha prevê mudanças significativas em relação à Rodada do Uruguai. A primeira consta nos parágrafos 1 a 12 do documento e refere-se à criação de um limite global para todas as políticas distorcivas, o chamado Overall Trade Domestic Support (OTDS). A segunda diz respeito aos parágrafos 13 a 29, os quais preveem as medidas de Caixa Amarela (AMS). Estas terão cortes bastante significativos e progressivos (quanto maior o limite atual, maior o corte previsto). Além disso, diferentemente do que ocorreu na Rodada do Uruguai, em que o limite era apenas global, na Rodada de Doha, haverá limite por produto. Uma terceira mudança identificada está prevista entre os parágrafos 30 a 34 e refere-se ao minimis que sofrerá redução. Para os países desenvolvidos, o limite será reduzido de $5 \%$ para $2,5 \%$ do valor da produção (redução de $10 \%$ para $6,7 \%$ no caso dos países em desenvolvimento). No caso dos países em desenvolvimento, sem AMS consolidado (não é o caso do Brasil), o de minimis continuará $10 \%$.

Já do parágrafo 35 ao 51, há a quarta mudança, a qual trata dos critérios para um programa ser classificado como pertencente à Caixa Azul. Os gastos de Caixa Azul passarão a ter limites, tanto globais quanto por produto. Na Rodada do Uruguai, esse tipo de gasto não tinha limitação alguma.

Por fim, entre os parágrafos 54 e 58, consta a quinta mudança, a qual prevê que haverá tratamento mais rigoroso no caso do Apoio Doméstico dado ao algodão. Cumpre salientar que o trecho do documento de modalidades que trata sobre esse tema, até hoje, não foi aceito pelos EUA. Abaixo segue figura 4 ilustrativa que resume as mudanças ocorridas no pilar de Apoio Doméstico:

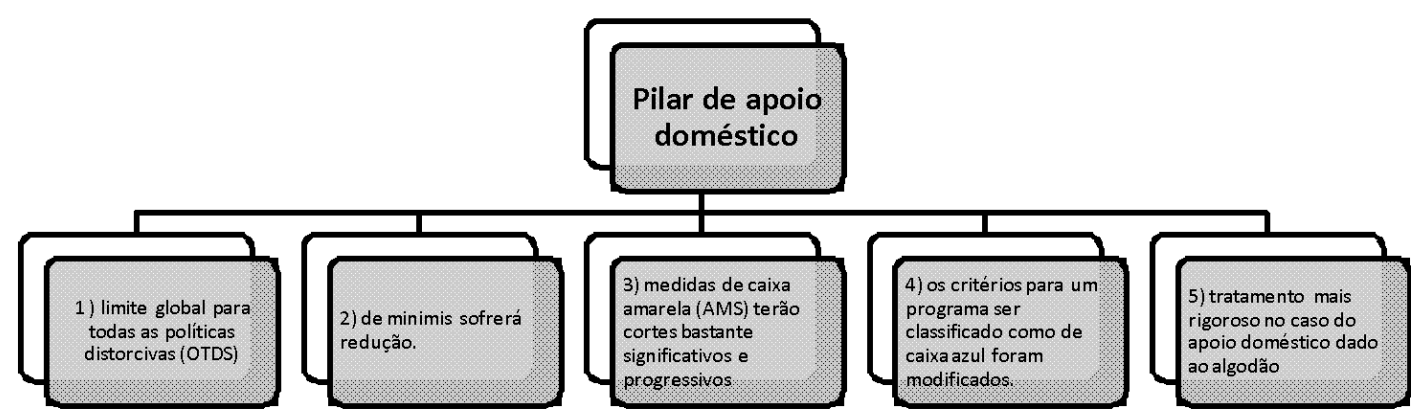

Figura 4 - Mudanças ocorridas no Pilar de Apoio doméstico - Rodada de Doha.

Fonte: elaboração própria.

Ao longo dos anos, a União Européia implementou reformas na sua política agrícola que efetivamente fizeram com que os seus gastos atuais ficassem quase totalmente adequados a um eventual acordo da Rodada de Doha no pilar de Apoio Doméstico. 
Carmona (2011) comenta que o caso dos EUA é bem diferente. Eles efetivamente precisarão implementar reformas significativas e não previstas na sua política agrícola, caso queiram se adequar a um novo acordo. $\mathrm{O}$ histórico de mudanças na Farm Bill não é animador. Mesmo em cenários favoráveis à agricultura, os americanos não se dispuseram a fazer reformas na sua política para deixá-la menos distorciva ao comércio. O atual cenário de preços agrícolas em alta vem fazendo com que os seus gastos fiquem muito abaixo dos gastos históricos. Entretanto, mesmo mantido esse cenário, os americanos terão que fazer reformas profundas nas políticas de produção dos lácteos, açúcar e algodão, para se adequar a um eventual acordo de Doha. Reformas para esses setores não estão previstas pelos americanos, a menos que a Rodada de Doha force-os a efetuar mudanças.

Com relação aos Subsídios às Exportações, o documento de modalidades prevê o fim destes até o final de 2013 para produtos agrícolas, no caso de países desenvolvidos. Carmona (2011) explica que, como há outras formas de conceder subsídios à exportação, além do subsídio clássico - como é o caso dos créditos à exportação concedidos em condições mais favoráveis que as condições de mercado -, o acordo da Rodada Doha prevê disciplinas bem mais rígidas para esse tipo de concessão. $\mathrm{O}$ autor reforça ainda que o pilar de Subsídios à Exportação é o mais fácil de tratar da negociação, pois apenas alguns poucos membros se valem deles, mas todos concordam que eles devem ser eliminados com a conclusão da Rodada de Doha.

Além desses pilares, esta rodada tem a intenção de levar ao fim a Salvaguarda Especial (SSG). Mas, para os países em desenvolvimento, está prevista a criação do Mecanismo de Salvaguarda Especial (SSM). Este é dispositivo a que os países em desenvolvimento poderão recorrer no caso de surtos de importação ou quedas acentuadas de preços dos produtos importados.

Carmona (2011) lembra que as divergências entre os EUA e a Índia sobre esse mecanismo foram as causas principais do fracasso nas negociações agrícolas em 2008. Enquanto os indianos queriam um mecanismo bastante frouxo para que eles pudessem facilmente elevar suas tarifas, inclusive acima dos níveis consolidados hoje, os EUA não aceitavam que a Rodada de Doha pudesse levar as tarifas maiores que as atuais para os exportadores americanos. Cumpre destacar que o texto apresentado no documento de modalidades sobre esse tema ainda aguarda consenso.

Esse assunto criou divergências até mesmo dentro do governo brasileiro. Enquanto o MAPA adota o princípio defendido pelos americanos, ou seja, que a Rodada de Doha não deve permitir que as tarifas aplicadas no futuro sejam mais elevadas que as praticadas atualmente; o MDA defende o ponto de vista dos indianos, os quais a tese de que há produtos que, sob o ponto de vista da segurança alimentar e da agricultura familiar, estão acima de interesses meramente comerciais. Carmona (2011) afirma que, tendo em vista essas divergências internas, o posicionamento do Brasil tem sido o de neutralidade, demonstrando claro interesse que o Acordo Agrícola seja concluído, independentemente do resultado obtido para o Mecanismo de Salvaguarda Especial. 


\section{Considerações finais}

Em suma, os fatos mostram que o mundo passou por um processo de reestruturação da ordem internacional, visando resolver problemas oriundos da grande depressão da década de 1930. As necessidades econômicas mundiais, no final da II Guerra, permitiram que fosse reforçada a ideologia defensora do livre comércio e o modelo capitalista. Essa reestruturação mundial reforçou-se nos acordos de Bretton Woods, nos quais foram criados o FMI, o Banco Mundial e a OIC. Esta última foi idealizada, mas não implementada, dando lugar ao GATT que se tornou permanente por quase 50 anos e serviu para que o mundo, através de discussões em oito rodadas de negociações, criasse condições para que os países reforçassem as relações comerciais multilaterais.

Cumpre ressaltar que, nas discussões do GATT, durante as sete primeiras rodadas, houve dificuldades de inserção de temas ligados à agricultura. Foi somente com a Rodada do Uruguai que o tema da liberalização agrícola pode ser inserido de maneira mais intensa nas discussões. Naquele momento, estabeleceu-se um Acordo Agrícola visando a regulamentação da agricultura através de três modalidades: o Acesso a Mercados, Apoio Doméstico e Subsídios à Exportação, além de uma Cláusula da Paz. O Acordo Agrícola possibilitou que a agricultura fosse formalmente incluída nas discussões do GATT, abrindo espaço para que países em desenvolvimento, como o Brasil, pudessem reivindicar maior liberalização agrícola para seus produtos.

No final da década de 1980, com o fim da Guerra Fria e a queda do Muro de Berlim, houve modificações no quadro internacional, o que deu ênfase ao crescimento do mundo capitalista. Assim, surgiu a OMC que completou o tripé planejado em Bretton Woods. Na Rodada de Doha, foram discutidos temas, como os da área agrícola, de grande importância e de muito interesse para os países em desenvolvimento.

Enfim, observa-se que, no que se refere às discussões de Acesso a Mercado na Rodada de Doha, estas permitiram avançar nas negociações agrícolas. A redução tarifária será feita por fórmulas, buscando resolver problemas de picos tarifários da Rodada do Uruguai. Os países em desenvolvimento também terão que cortar as tarifas e não apenas consolidá-las. O documento traz novas regras para produtos sensíveis, sendo que o tratamento à estes produtos será mais ameno, pois se prevê redução nos cortes e expansão das cotas. A Rodada lança ainda na discussão temas como: escalada tarifária, produtos tropicais, erosão de preferências, simplificação das tarifas. No entanto na busca por uma maior liberalização comercial, a Rodada de Doha reserva espaço também para a discussão de novos temas.

\section{Referências}

ARAÚJO, L. R.; JANK, M. S. A agenda brasileira nas negociações agrícolas da Rodada de Doha da OMC. Revista de Economia \& Relações Internacionais, São Paulo, v. 2, n. 3, p. 57-70, jul. 2003. 
BARRAL, W. De Bretton Woods a Hong Kong. Revista de Direito Econômico Internacional: RDEI, Florianópolis, n. 8, ago. 2005. Disponível em: http://www.iribr.com/hongkong/DE_BRETTON_WOODS_A_HONG_KONG.asp. Acesso em: 23 jun. 2010.

CARMONA, L. Comentários ao acordo agrícola da Rodada do Uruguai e ao Acordo de Modalidades da Rodada de Doha de dezembro de 2008. [mensagem pessoal]. Mensagem recebida por < luizcarmona@agricultura.gov.br> em 1 fev. 2011.

CARTA DE GENEBRA. Informativo sobre a OMC e a Rodada de Doha, Genebra: Missão Permanente do Brasil em Genebra, n. 3, 2002. Disponível em: <http://www.mre.gov.br/carta_genebra/cartadegenebra5_0pdf $>$. Acesso em: 20 maio 2009.

CERVO, A. L. A Organização Mundial do Comércio. Brasília: Thesaurus/FUNAG, 2008. Disponível em

: $<$ http://funag.gov.br/biblioteca/index.php?option=com_docman\&task=cat view\&gid= 43\&Itemid=41\&limitstart=10. Acesso em: 1 fev. 2010.

DI SENA JÚNIOR, R. Comércio internacional e globalização: a cláusula social na OMC. Curitiba: Juruá, 2006.

DICIONÁRIO DE TERMOS DE COMÉRCIO. Sistema de informação sobre comércio exterior (SICE). São Paulo: OEA/BID/CEPAL, 2011. Disponível em: www.eclac.org/.../1/.../Dictionary\%20Portuguese\%20FINAL\%20web.pdf . Acesso em: 10 abr. 2011.

FORSCHETE. M. Relações econômicas internacionais. São Paulo: Aduaneiras, 2001.

GONÇALVES, R. et al. A nova economia internacional: uma perspectiva brasileira. Rio de Janeiro: Campus, 1998.

GRIECO, F. A. O Brasil e a nova economia global. São Paulo: Aduaneiras, 2001.

INSTITUTO DE ESTUDOS DO COMÉRCIO E NEGOCIAÇÕES INTERNACIONAIS. Glossário ICONE. São Paulo: ICONE, 2011. Disponível em: <http://www.iconebrasil.org.br/pt/?actA=16\&areaID=14\&secaoID=29\&letraVC=O $>$. Acesso em: 10 dez. 2010.

KRUGMAN. P. R; OBSTFELD, M. Economia internacional, teoria e política. São Paulo: Makron Books, 2005.

MAIA, J. M. Economia internacional e comércio exterior. 8. ed. São Paulo: Atlas, 2003. 
MESQUITA. P. E. Multifuncionalidade e preocupações não-comerciais:

implicações para as negociações agrícolas na OMC. Brasília: FUNAG, 2005.

\section{ORGANIZAÇÃO MUNDIAL DO COMÉRCIO. Declaração Ministerial de Doha.}

Genebra: OMC, 2011. Disponível em:

<http://www.wto.org/spanish/tratop_s/dda_s/dda_s.htm\#declaration>. Acesso em: 10 jan. 2011.

RODRIGUES, T. S. F.; PAULA. N. M. A agricultura nas negociações multilaterais da Rodada Doha e suas implicações para o Brasil. Revista de Economia, Curitiba, v. 34, n. 2, p. 95-115, maio/ago. 2008.

SALVATORE, D. Economia Internacional. 6. ed. Rio de Janeiro: LTC, 1998.

SATO, E. De Gatt para a OMC e a agenda do Brasil no comércio internacional. In: OLIVEIRA, H. A.; LESSA, A. C. (Org.). Relações internacionais do Brasil: temas e agendas, v. 2. São Paulo: Saraiva, 2006. p. 125-158.

VIZENTINI, P. G. F. História do século XX. 3. ed. Porto Alegre: Leitura XXI, 2007.

VIZENTINI, P. G. F. O mundo pós-guerra fria: globalização, guerra ao terror e multipolarização. Porto Alegre: Leitura XXI, 2005.

WORD TRADE ORGANIZATION. Revised Modalities for Agriculture. Geneva: WTO, 2008. Disponível em:

http://www.wto.org/english/tratop_e/agric_e/agchairtxt_dez06_pdf

. Acesso em: 12 fev. 2011.

Tamara Silvana Menuzzi Diverio

Professora vinculada ao Curso de Mestrado Profissional em Desenvolvimento

Rural da Universidade de Cruz Alta (UNICRUZ). Possui Pós-Doutorado em

Economia pela Universidade de Évora, Portugal, Doutorado em

Desenvolvimento Rural pela Universidade Federal do Rio Grande do Sul,

Mestrado em Engenharia de Produção e Graduação em Ciências Econômicas

pela Universidade Federal de Santa Maria.

Rua: Senador Pasqualine, 36 - apto - 204 - Santa Cruz do Sul - RS. CEP:

96820050 - Brasil

E-mail: tamara.diverio@domalberto.edu.br

Recebido para publicação em junho de 2014

Aprovado para publicação em janeiro de 2015 